\title{
Conservation Triage Falls Short Because Conservation Is Not Like Emergency Medicine
}

\author{
John A. Vucetich ${ }^{1 *}$, Michael Paul Nelson ${ }^{2}$ and Jeremy T. Bruskotter ${ }^{3}$ \\ ${ }^{1}$ School of Forest Resources and Environmental Sciences, Michigan Technological University, Houghton, MI, United States, \\ ${ }^{2}$ Department of Forest Ecosystems and Society, Oregon State University, Corvallis, OR, United States, ${ }^{3}$ School of \\ Environment and Natural Resources, Ohio State University, Columbus, $\mathrm{OH}$, United States
}

OPEN ACCESS

Edited by:

James Guy Castley,

Griffith University, Australia

Reviewed by:

Alexandra J. R. Carthey,

Macquarie University, Australia

Stuart Pimm,

Duke University, United States

*Correspondence:

John A. Vucetich

javuceti@mtu.edu

Specialty section:

This article was submitted to

Conservation,

a section of the journal

Frontiers in Ecology and Evolution

Received: 18 February 2017

Accepted: 25 April 2017

Published: 23 May 2017

Citation:

Vucetich JA, Nelson MP and Bruskotter JT (2017) Conservation

Triage Falls Short Because

Conservation Is Not Like Emergency

Medicine. Front. Ecol. Evol. 5:45.

doi: 10.3389/fevo.2017.00045
Conservation triage, as a concept, seems to have been born from analogizing circumstances that characterize conservation with triage, as the concept applies to emergency medicine. Careful consideration-facilitated through the aid of formal argumentation-demonstrates the critical limitations of the analogy. Those limitations reveal how the concept of conservation triage falls short. For example, medical triage presupposes that resources available for an emergency are limited and fixed. By contrast, the resources available for conservation are not fixed. Moreover, the ethics of prioritization in medical triage is characterized by there being universal agreement on the moral value of the patients. However, in conservation there is not universal agreement on the value of various objects of conservation concern. The looming importance of those features of conservation-disputed values and unfixed resources-make conservation triage a largely un-useful concept.

Keywords: conservation ethics, argument analysis, cost-benefit analysis, consequentialism, care ethics

\section{INTRODUCTION}

Conservation triage is usefully characterized as a strategic "process of prioritizing the allocation of limited resources to maximize conservation returns, relative to the conservation goals, under a constrained budget... achieved by explicitly accounting for the costs, benefits and likelihood of success of alternative conservation actions..." (Bottrill et al., 2008). Some argue that conservation triage is appropriate because of the "astronomical" shortfall in resources allocated to conservation (e.g., Balmford et al., 2003; Bottrill et al., 2008; McCarthy et al., 2012). As such, some goals of conservation will go unmet. Given that indisputable circumstance, the argument goes, we should strategically select which conservation goals should be denied. The rejection of conservation triage has been labeled "unconscious triage" and portrayed as "the worst of all possible choices" (Nijhuis, 2013, quoting Tim Male, Vice President at Defenders of Wildlife; see also Martin et al., 2012).

Views that are supportive of conservation triage are contested. A countervailing perspective is that conservation triage is inappropriate because it promotes a defeatist attitude; because it inappropriately presumes we can accurately predict which conservation goals are unattainable, given the available resources; and because it is simply wrong to forego any aspect of conservation given that the moral value of conservation is so great.

Importantly, much of the support for conservation triage seems associated with the idea that "rather than being an ethical position, conservation triage is simply an unavoidable step in the process of efficiently allocating resources when budgets are constrained" (Bottrill et al., 2008). There 
is value in acknowledging that academicians with expertise in the scholarly field of ethics consider their field to be about the formal analysis of ethical propositions, where an ethical proposition can be expressed, for example, as "We should (or should not)..." Moreover, ethical decisions are decisions about how one ought to behave when the behavior in question has consequences for other morally-relevant beings or entities. As such, we are unsure how one could conclude that conservation triage (opposed to unconscious triage) is not an ethical decision. For the same reason, we are unsure how one could conclude that decisions made within a conservation triage framework are not ethical decisions.

Some of the conflict might be resolved (at least clarified) by exposing conservation triage to formal argument analysis, which is a basic tool of scholarly ethics (Nelson and Vucetich, 2012). Argument analysis has been usefully applied to other concerns in conservation ethics, including advocacy by scientists (Nelson and Vucetich, 2009) and predator control (Vucetich and Nelson, 2014). The first step in argument analysis is to convert a rationale (for conservation triage) into a formal argument with premises and a conclusion. The second step is to evaluate whether (i) all the premises are true or appropriate, and (ii) the conclusion follows from the premises. By the rules of logic, a conclusion is supported by an argument if and only if both conditions hold. One of the benefits of argument analysis is to clarify points of disagreement. Here is a nascent argument for conservation triage which we can begin to analyze:

P1. Conservation is a multifaceted endeavor, the realization of which requires vast resources, financial, and otherwise. P2. The resources allocated to conservation are insufficient. $C$. Therefore, we should thoughtfully and strategically prioritize the allocation of those scarce resource; doing so entails the willful denial of many conservation goals.

The conclusion of this argument, then, is to endorse conservation triage. One could add or revise premises to the argument, and doing so may be critical. However, arguments are like scientific models in the sense that they should be made as simple as possible (though no simpler than required). It is often better to consider a simpler argument; then, revise and add premises to the argument after some analysis shows the value of doing so.

\section{AGENTS OF CONSERVATION}

Consider the word "we" in the argument's conclusion. The referent of "we" is unspecified. Insight might arise from considering who "we" refers to.

Conservation is manifest in society through a variety of actors or agents that affect change. These agents include, for example, individual humans, certain non-governmental organizations (NGOs), government agencies whose purview is conservation, and entire societies (such as states, nations, or sets of nations). For the conclusion to be reliable, P2 (about scarce resources) must be true. The truth of P2 may depend on the agent of conservation of whom we are speaking.
First, consider an individual human whose resources are scant with respect to the resources required to affect all conservation. (Please bear with us for what may seem pedantic. This is an important starting place for more sophisticated ideas to follow.) The person with scant resources is unable to attend most conservation goals, necessarily and indisputably. So an individual person must decide the tiny portion of conservation to which they will direct their effort and resources. As such, it would be wise for an individual to consider that allocation thoughtfully.

Similarly, consider an NGO devoted to some aspect of conservation. Their circumstance is essentially like that of an individual: their resources are scant in comparison to the cost of conservation. The NGO has a choice-more properly, the leaders of the NGO have a choice-about what aspect(s) of conservation to allocate their resources; but they do not have a choice about whether to selectively allocate resources. As such, it would be wise for an NGO to strategically consider where to allocate its resources.

Now consider-as an agent of conservation-an entire citizenry, such as a nation. Recall, that the critical premise of conservation triage is the premise that resources are far too scarce. For a social entity as large and encompassing as an entire nation, the appropriateness of premise $\mathrm{P} 2$ is arguable. $\mathrm{P} 2$ is likely expressed too simply to be judged true or false, or too simply to support the conclusion.

In particular, if the agent of conservation is an entire citizenry, then P1 and P2 likely support a conclusion something like:

C. These citizens have a genuine interest in thoughtful and strategic allocation of scarce resource.

However, if the agent is an entire nation, then the argument (P1 and P2) likely does not support the conclusion that many conservation goals should be willfully set aside. An important set of premises that had been missing from the argument is:

P3a. The resources that a nation allocates to conservation are not fixed. P3b. The allocation of additional resources toward conservation depends on persuading the citizenry that the goals of conservation should override other societal interests.

The truth and relevance of P3 casts a deep shadow on the conclusion that "conservation goals should be willfully denied."

A related idea is that limited resources is a proximate cause of conservation failures and the ultimate cause is a citizenry that does not sufficiently value conservation. By this view, the inadequate allocation of limited resources is a consequence of undervaluing conservation.

The last agent that we consider is a government agency acting within a nation or state, whose purview is conservation. Because the funding allocated to such an agency is typically not determined by the leaders of the agency, funding is scant in relation to the cost of conservation. As such, selective allocation is inevitable and strategic allocation would be in the genuine interest of the agency's constituents.

Strategic allocation of resources is, however, only one responsibility of such an agency. A second responsibility is to advocate to its constituents the need to allocate enough resources for conservation. Given the severity of the shortfall, this second 
responsibility is arguably more critical than efficient allocation. To think otherwise may be analogous to arranging deck chairs on a sinking ship in the most efficient manner.

The key point is this-an agency using the language and rhetoric of conservation triage in service of its one responsibility, may be undermining its other responsibility-in spite all intentions to the contrary.

\section{COMPARISON WITH EMERGENCY MEDICINE}

Consider a hypothetical incident: Two paramedics with first aid supplies arrive at a scene with dozens of injured people. There is a relatively short, but critical period of time during which the paramedics and their supplies are the only resources available for treating the victims. For emphasis, the available resources are limited and fixed. Sufficient resources are being brought to bear as fast as humanly possible. In the meantime, some people are going to die, but the number of people who die depend on how the paramedics allocate their medical assistance. This scene represents salient elements of triage as the concept is applied in emergency medicine.

There has been an ongoing effort to explain and justify conservation triage by making-sometimes elaboratecomparisons to triage as the concept is applied in emergency medicine. For example, Wilson and Law (2016) write: "Our aim is to contrast the concept and practice of triage in emergency medicine and conservation in order to discern why it is more accepted in medicine yet polarized in conservation..."

The analogy fails to convince those opposed to conservation triage likely for several interrelated reasons. First, in the emergency medicine scenarios to which triage is applied there is no question that the resources available are insufficient and fixed. In conservation, by contrast, resources are not fixed. Unlike the paramedics who arrive at the scene of an medical emergency, we-as a society-can decide to allocate more resources to conservation. Also, the emergency medicine crisis we described will pass within minutes, while most conservation crises will play out over many years.

The analogy between conservation and triage as the concept is applied in emergency medicine fails short in another critical way. That is, in emergency medicine scenarios, there is essentially universal agreement about the moral value of what is at stake, i.e., human life and well-being. Again, by contrast, there is not universal agreement among citizens about how valuable conservation is or the reasons why it is valuable. Those differences make the comparisons to emergency medicine of limited value and undermine the appropriateness of conservation triage; the next section is devoted to explaining why.

\section{THE ETHICS OF PRIORITIZATION}

Supporters of conservation triage also seem to be in broad agreement that it "is achieved by explicitly accounting for the costs, benefits, and likelihood of success of alternative conservation actions" (Bottrill et al., 2008). That idea is formalized by the claim that resources should be allocated to one conservation project as opposed to another, according to the efficiency $(E)$ of the project, where $E=(V \times B \times S) / C$ and $C$ is the cost of the project, $S$ is the probability of realizing the project's goal, given the expenditure of that cost, $B$ is the benefit of the project to the particular object of conservation concern (say, an endangered species), and $V$ is the overall value of this particular object of conservation concern (e.g., Kilham and Reinecke, 2015; see also Bottrill et al., 2008).

Some scholars have expressed concern for the tendency to overestimate the accuracy of cost-benefit analyses, in part, because we overestimate our confidence in predicting the future state of ecosystems (Holling and Meffe, 1996). That shortcoming would be inherited by any version of conservation triage that relied heavily on cost-benefit analysis. While that concern is important, its discussion is beyond the scope of this essay.

Public discourse on conservation reflects vigorous debate about the value different people assign to various elements of nature and its conservation. That debate includes, for example, whether non-human elements of nature possesses intrinsic value or if those elements are of value only to humans (Vucetich et al., 2015; Batavia and Nelson, 2017). That debate has critical implications for how much value ( $V$ in the efficiency equation) would be assigned to various elements of nature. Other important debates pertain to the conflicts that conservation creates with animal welfare (Paquet and Darimont, 2010), social justice (Brown, 2003), and economic growth (Czech et al., 2000). One's perspective on those debates would also greatly influence assignment given to value $(V)$ for various conservation projects.

Those circumstances indicate, at least to us, that one's view on what to prioritize in conservation would be depend largely on the disparate assignments to $V$ that various people would give to various aspects of nature and conservation. Also note that the above mentioned debates occur within the conservation community. The disparateness in assignments to $V$ increase greatly when one takes account of citizens without a basic appreciation for nature or conservation.

The concern is that conservation triage-insomuch as it is represented by that efficiency equation, $E=(V \times B \times$ $S) / C$-suggests that the greatest challenge to conservation is a problem for which conservation triage is not well suited to handle. That is, the challenge is undervaluing conservation. Or perhaps the challenge, more precisely is, heterogeneity among citizens concerning the value of various conservation goals. The rhetoric and concepts associated with triage are not well-tailored to advancing the discourse on debates so deeply steeped in unresolved values.

Supporters of conservation triage routinely highlight the importance of clearly articulated goals. They also mention the importance of stakeholder processes aimed at developing goals. However, the greatest challenge to conservation is, perhaps, the unmet need for robust justifications that persuade those who are not in agreement with various goals of conservation. That problem exists within the conservation community as well as between the conservation community and the rest of society. The concern is that the rhetoric and concepts of conservation 
triage are not especially well-suited for such handling of valuesat best. At worst, it is a dangerous for deceptively undermining conservation.

\section{CONSERVATION TRIAGE IN ACTION}

To illustrate how these ideas can be manifest in the real world, consider red wolf (Canis rufus) conservation. In 2016, the United States Fish and Wildlife Service (USFWS) announced significant adjustments in its approach to conserving red wolves (USFWS, 2016). The changes include a significant shift of effort away from conserving the wild population. The underlying rationale for the adjustment is "maximizing efficient use of Services resources." While conservation triage calls for an explicit analysis of efficiencies of various possible conservation strategies, no such analysis pertaining to red wolves has been shared with the public. Moreover, a reasonable case can be made that the decision was the result of intense political opposition to wolves by local landowners and state governments (Fears, 2016). If so, the decision was not driven by a prioritizing of one conservation project over another on the grounds of efficiency. Rather the decision was driven by contempt for conservation. Then the USFWS covered that explanation with the language of conservation triage; all the while there is an implicit and unresolved disagreement over the value $(V)$ of a wild population of red wolves.

The rhetoric of conservation triage has also been used in the context of conserving woodland caribou (Rangifer tarandus) in Alberta, Canada. In particular, Schneider et al. (2010) conclude that preventing habitat degradation by the petroleum and forestry industries would incur an "opportunity cost... in excess of 100 billion dollars" [italics added]. They also conclude that a wolf-control program (intended to reduce predation on caribou) would cost only on the order of "tens of millions of dollars." That analysis-steeped in the rhetoric of conservation triage and explicitly motivated by concerns that Albertans have "limited capacity" for manifesting conservation-has been cited as justification for decisions by the Canadian province to focus caribou conservation on wolf control (and maintaining a fenced population of caribou) and to forego the protection of habitat. Nevertheless, most familiar with the circumstance believe that caribou cannot be properly conserved without protecting habitat (e.g., Proulx and Powell, 2016). Our concern is that the language of conservation triage has been used to the effect of obfuscating whether the people of Alberta-as represented by their government-lack the capacity to protect habitat or whether they place insufficient value $(V)$ on caribou habitat compared to the value they place on the petroleum and forestry industries.

Conservation triage also lurks beneath the USFWS's the legal-political process for determining whether a species should be listed (i.e., protected) or delisted by the U.S. Endangered Species Act (ESA). The listing of a species is supposed to be acknowledgment that a species meets the legal definition of threatened or endangered. Being listed obligates the USFWS (acting on behalf of U.S. citizens) to take several basic protective actions. One of the key protective actions is a prohibition on "take," a legal term meaning to "harass, harm, pursue, hunt, shoot, wound, kill, trap, capture, or collect, or to attempt to engage in any such conduct." Take has also come to include activities that lead to the degradation of habitat. A second protective element is a legal obligation to develop and implement a plan for recovering each listed species.

The USFWS has a prioritization system allowing it to forego those obligations for a particular listed species if limited resources preclude the USFWS from fulfilling those obligations. That prioritization system-criticized for too often being implemented inappropriately (Evans et al., 2016) - is a codification of conservation triage allowing the USFWS to provisionally forego an obligation without dismissing the obligation.

In addition, (and this is where the troubling parts begin) the USFWS may determine that a species should be listed but decide not to do so because resources are too scarce to list the species and the protection of other species is of greater priority. These decisions are referred to in legal shorthand as "warranted but precluded." By 2011, the listing of 251 species was judged to be warranted, but precluded. Concerns about the abuse of warranted-but-precluded decisions have been widely noted (Greenwald et al., 2005; Smith, 2011; Puckett et al., 2016). In recent years, at least some resolution to those concerns has been realized, but only because of a legal settlement requiring the USFWS to make final listing decisions for all 251 species by 2017 (Bricketto, 2011; Puckett et al., 2016).

Since that settlement, the director of the USFWS has expressed views which raise similar concerns over the legal-political process of delisting species. A species is to be delisted only if it no longer fits the legal definition of threatened or endangered and if the threats which caused the species to have been threatened or endangered have been mitigated. In particular, the director indicated that delisting decisions should also take account of the fact that decisions not to delist take away from the resources that can be devoted to other species of higher priority because conservation resources are scarce (Nelson and Vucetich, 2014).

The concern with these circumstances surrounding the legalpolitical process of listing and delisting is this: Because the USFWS has a prioritization system for allocating resources to listed species, being listed is no assurance that resources will be devoted to the conservation of a particular species. However, being listed is absolutely critical as acknowledgment of a conservation failure and acknowledgment of our obligation to address that failure. If we fail to meet a particular obligation because of scarce resource-then fine (perhaps). But failing to meet an obligation is not the same as absolving an obligation. When a species is unjustly delisted (or unjustly denied of being listed) we are not merely failing to address a failure-we are denying that a failure even exists.

Moreover, "take" (as defined by the ESA) is illegal if a species is listed. Even if the prohibition on take cannot be enforced (e.g., prosecution of poaching), the act is still illegal. Being illegal is liable to have at least some positive conservation effect. For example-and we recognize that elements of what follows is controversial-if gray wolves in the northern Rocky mountain states had not been prematurely delisted, then state governments would not have implemented harvests that impede recovery of 
the species; the states would have refrained because harvesting would have been illegal for violating a prohibition on take (Bruskotter et al., 2014).

Finally, we would not decide to legalize instances of murder in the U.S. because the inability to allocate sufficient resources contributes to a third of murder cases going unsolved (Kaste, 2015). For the same reason, we should not legalize the take of a species that fits the legal definition of endangered simply because we do not have the resources to enforce the law.

Collectively, these examples raise concerns that rhetoric associated with conservation triage is used in the real world, not for the efficient allocation of scarce conservation resources, but to rationalize the abdication of obligations to conservation.

\section{COMPARISON WITH SOCIAL JUSTICE}

Conservation triage also implies moral judgment against those supporting aspects of conservation deemed by others to be low priority, e.g., the conservation of charismatic species that are otherwise less valuable. The judgment is that those people are misallocating scarce resources and contributing to "unconscious triage."

With that context, consider a comparison between two aspirations-conservation and social justice. Conservation is multifaceted, not fully realized, and broadly (though not universally) supported as a value in society. Social justice is usefully characterized in the same way-multifaceted, not fully realized, and broadly supported. Now consider two agents (they could be individuals or NGOs) who care about social justice. Neither has enough resources to fully manifest social justice. One decides-for whatever reason-to support causes aimed at reducing starvation. The other decides-for whatever reason-to support causes aimed against human trafficking. We are unaware of any rationale that would lead to admonishing either agent on grounds that their cause is less important than other causes and therefore represents a misallocation of the scant resources to social justice.

Those ideas applied to social justice can be generalized in a manner that would pertain to conservation. The claims to consider are: a person is culpable for the breadth and depth of their care for others (human and non-human), and culpable for being open to new knowledge and developing skills to better manifest (and direct) the care that motivates their actions. But to judge someone harshly for the idiosyncratic circumstances that brought a person to manifest their care for one cause rather than another-that seems unjust.

Along the same lines, there is a moral obligation for those so educated to teach others about the most neglected aspects of

\section{REFERENCES}

Balmford, A., Gaston, K. J., Blyth, S., James, A., and Kapos, V. (2003). Global variation in terrestrial conservation costs, conservation benefits, and unmet conservation needs. Proc. Natl. Acad. Sci. U.S.A. 100, 1046-1050. doi: $10.1073 /$ pnas. 0236945100 conservation, as a means of encouraging others to contribute to those aspects of conservation. Conservation triage does not seem especially valuable for promoting the moral obligations mentioned above-indeed, it could undermine them.

\section{CONCLUSION}

Others have raised different kinds of criticism against conservation triage (e.g., Pimm, 2000). While implicitly mindful of those criticisms, this short essay is not intended to serve as a comprehensive review of such criticisms, nor should this essay be taken as passing judgment on the robustness or relative merit of those prior criticisms. Our criticism of conservation triage is limited to the points raised herein.

Supporters of conservation triage emphasize two principles, i.e., clear articulation of goals and the strategic allocation of scant resources. Those principles are indisputably valuable to any organization, including conservation organizations. Those two principles underlie all strategic planning processes. They are not exclusive to scenarios to which triage is traditionally applied (emergency medicine or disaster relief).

Moreover, the rhetoric associated with conservation triage has some legitimate shortcomings. First, conservation triage may undermine a conservation agency's other mandate to advocate for the allocation of more resources to conservation. Second, conservation triage is not well-suited (or even designed) to better understand how and why we should value non-human nature and its conservation. Conservation triage's greatest contribution may be as a vehicle for demonstrating that scant resources is not the greatest threat to conservation. Rather, the greatest threats to conservation are values and policies that are antithetical to conservation. If so, then conservation triage may be akin to a famous metaphor in philosophy, i.e., Wittgenstein's ladder. That is, conservation triage is a ladder that may be useful for gaining a new perspective; but after ascending the ladder, it is best to throw it away.

While many aspirations of conservation will be lost in the near future, the great challenge of conservation is not deciding which ones to deny. The most important and possibly most urgent challenge is figuring out how to inspire a deeper and broader sense of care for others-humans and non-humans, alike.

\section{AUTHOR CONTRIBUTIONS}

All three co-authors contribute equally to the ideas of the manuscript. JV wrote the first draft of the manuscript. All three authors contributed equally to transforming the draft manuscript into the final manuscript.
Batavia, C., and Nelson, M. P. (2017). For goodness sake! What is intrinsic value and why should we care? Biol. Conserv. 209, 366-376. doi: 10.1016/j.biocon.2017.03.003

Bottrill, M. C., Joseph, L. N., Carwardine, J., Bode, M., Cook, C., Game, E. T., et al. (2008). Is conservation triage just smart decision making?. Trends Ecol. Evol. 23, 649-654. doi: 10.1016/j.tree.2008.07.007 
Bricketto, M. (2011). US Settles with WildEarth in Endangered Species MDL. Law360. Available online at: https://www.law360.com/articles/244204/ us-settles-with-wildearth-in-endangered-species-mdl (Accessed March 23, 2017).

Brown, K. (2003). Three challenges for a real people-centred conservation. Global Ecol. Biogeogr. 12, 89-92. doi: 10.1046/j.1466-822X.2003. 00327.x

Bruskotter, J. T., Vucetich, J. A., Enzler, S., Treves, A., and Nelson, M. P. (2014). Removing protections for wolves and the future of the US Endangered Species Act (1973). Conserv. Lett. 7, 401-407. doi: 10.1111/conl.12081

Czech, B., Krausman, P. R., and Devers, P. K. (2000). Economic associations among causes of species endangerment in the United States: associations among causes of species endangerment in the United States reflect the integration of economic sectors, supporting the theory and evidence that economic growth proceeds at the competitive exclusion of nonhuman species in the aggregate. Bioscience 50, 593-601. doi: 10.1641/0006-3568(2000)050[0593:EAACOS]2.0. $\mathrm{CO} ; 2$

Evans, D. M., Che-Castaldo, J. P., Crouse, D., Davis, F. W., Epanchin-Niell, R., Flather, C. H., et al. (2016). Species recovery in the United States: increasing the effectiveness of the Endangered Species Act. Issues Ecol. 2016.

Fears, D. (2016). Red Wolves Will Still Be Protected - But More By Zoos Than in the Wild. Washington Post. Available online at: http://www.washingtonpost., com/news/energy-environment/wp/2016/09/12/red-wolves-will-still-beprotected-but-more-by-zoos-than-in-the-wild/?utm_term $=.2 \mathrm{~b} 20244 \mathrm{f5} 5 \mathrm{c} 5 \mathrm{~b}$ (Accessed March 31, 2017).

Greenwald, D. N., Suckling, K. F., and Taylor, M. (2005). "The listing record," in The Endangered Species Act At Thirty: Renewing the Conservation Promise, Vol. 1, eds D. D. Goble, J. M. Scott, and F. W. Davis (Washington, DC: Island Press), 392.

Holling, C. S., and Meffe, G. K. (1996). Command and control and the pathology of natural resource management. Conserv. Biol. 10, 328-337. doi: 10.1046/j.1523-1739.1996.10020328.x

Kaste, M. (2015). Open Cases: Why One-Third of Murders in America Go Unresolved. National Public Radio. Available online at: http://www.npr.org/ 2015/03/30/395069137/open-cases- why-one-third- of-murders-in-americago- unresolved (Accessed March 24, 2017).

Kilham, E., and Reinecke, S. (2015). "Biggest Bang for Your Buck": Conservation Triage and Priority-Setting for Species Management in Australia and New Zealand, INVALUABLE Policy Brief, 0115. Albert-Ludwigs-Universität Freiburg, Freiburg.

Martin, T. G., Nally, S., Burbidge, A. A., Arnall, S., Garnett, S. T., Hayward, M. W., et al. (2012). Acting fast helps avoid extinction. Conserv. Lett. 5, 274-280. doi: 10.1111/j.1755-263X.2012.00239.x

McCarthy, D. P., Donald, P. F., Scharlemann, J. P., Buchanan, G. M., Balmford, A., Green, J. M., et al. (2012). Financial costs of meeting global biodiversity conservation targets: current spending and unmet needs. Science 338, 946-949. doi: $10.1126 /$ science. 1229803

Nelson, M. P., and Vucetich, J. A. (2009). On advocacy by environmental scientists: what, whether, why, and how. Conserv. Biol. 23, 1090-1101. doi: $10.1111 /$ j.1523-1739.2009.01250.x
Nelson, M. P., and Vucetich, J. A. (2012). "Environmental ethics for wildlife management," in Human Dimensions of Wildlife Management, eds D. J. Decker, S. J. Riley, and W. Siemer (Baltimore, MD: Johns Hopkins University Press), 223-237.

Nelson, M. P., and Vucetich, J. A. (2014). The Future of Conservation and the Tragedy of Triage. The Huffington Post. Available online at: http://www. huffingtonpost.com/michael-p-nelson/the-future-of-conservatio_b_5870568. html (Accessed March 19, 2015).

Nijhuis, M. (2013). Conservation Triage: Which Species Should Be Saved. Slate. Available online at: http://www.slate.com/articles/health_and_science/animal_ forecast/2013/02/conservation_triage_which_species_should_be_saved.html (Accessed February 14, 2017).

Paquet, P. C., and Darimont, C. T. (2010). Wildlife conservation and animal welfare: two sides of the same coin. Anim. Welf. 19, 177-190.

Pimm, S. L. (2000). Against triage. Science 289, 2289-2289. doi: $10.1126 /$ science. 289.5488 .2289

Proulx, G., and Powell, R. A. (2016). Build habitats, not fences, for caribou. Science 353, 1506-1507. doi: 10.1126/science.aai9328

Puckett, E. E., Kesler, D. C., and Greenwald, D. N. (2016). Taxa, petitioning agency, and lawsuits affect time spent awaiting listing under the US Endangered Species Act. Biol. Conserv. 201, 220-229. doi: 10.1016/j.biocon.2016.07.005

Schneider, R. R., Hauer, G., and Boutin, S. (2010). Triage for conserving populations of threatened species: the case of woodland caribou in Alberta. Biol. Conserv. 143, 1603-1611. doi: 10.1016/j.biocon.2010.04.002

Smith, K. M. (2011). Abuse of the warranted but precluded designation: a real or imagined purgatory. Southeast. Environ. Law J. 119.

USFWS (U.S. Fish and Wildlife Service) (2016). Memorandum to the Regional Director, Southeast Region. RE: Recommended Decisions in Response to Red Wolf Recovery Program Evaluation. Available online at: https://www.fws.gov/ redwolf/docs/recommended-decisions-in-response-to-red-wolf-recoveryprogram- evaluation.pdf

Vucetich, J. A., Bruskotter, J. T., and Nelson, M. P. (2015). Evaluating whether nature's intrinsic value is an axiom of or anathema to conservation. Conserv. Biol. 29, 321-332. doi: 10.1111/cobi.12464

Vucetich, J. A., and Nelson, M. P. (2014). "Wolf hunting and the ethics of predator control," in The Oxford Handbook of Animal Studies, ed L. Kalof (Oxford, UK: Oxford University Press), 1-15. doi: 10.1093/oxfordhb/9780199927142.013.007

Wilson, K. A., and Law, E. A. (2016). Ethics of conservation triage. Front. Ecol. Evol. 4:112. doi: 10.3389/fevo.2016.00112

Conflict of Interest Statement: The authors declare that the research was conducted in the absence of any commercial or financial relationships that could be construed as a potential conflict of interest.

Copyright $\odot 2017$ Vucetich, Nelson and Bruskotter. This is an open-access article distributed under the terms of the Creative Commons Attribution License (CC BY). The use, distribution or reproduction in other forums is permitted, provided the original author(s) or licensor are credited and that the original publication in this journal is cited, in accordance with accepted academic practice. No use, distribution or reproduction is permitted which does not comply with these terms. 